\title{
Dense $\mathrm{MoS}_{2}$ Micro-Flowers Planting on Biomass-Derived Carbon Fiber Network for Multifunctional Sulfur Cathodes
}

\author{
Rameez Razaq, ${ }^{[a, b, c]}$ Nana Zhang, ${ }^{[b]}$ Ying Xin, ${ }^{[b]}$ Qian Li $^{[b]}$ Jin Wang, ${ }^{[b]}$ and \\ Zhaoliang Zhang* ${ }^{*[a, b]}$
}

\begin{abstract}
The significant challenge in lithium-sulfur batteries (LSBs) arises from low conductivity of sulfur cathode, loss of active sulfur species due to less anchoring sites and sluggish redox kinetics of lithium polysulfides (LPSs). Herein, the dense $\mathrm{MoS}_{2}$ microflowers assembled by cross-linked 2D $\mathrm{MoS}_{2}$ nanoflakes planting on biomass-derived carbon fiber (CF) network $\left(\mathrm{MoS}_{2} / \mathrm{CFs}\right)$ are fabricated as multifunctional sulfur cathodes of LSBs. The 2D $\mathrm{MoS}_{2}$ nanoflakes supported on CF provide abundant anchoring sites for strong adsorption, while the 3D flowerlike structure prevents lamellar aggregation of 2D $\mathrm{MoS}_{2}$ nanoflakes. Importantly, the dense $\mathrm{MoS}_{2}$ micro-flowers planting on the network
\end{abstract}

\section{Introduction}

Lithium-sulfur batteries (LSBs) have gained immense consideration in the practical applications of electric vehicles, satellites, and other portable energy-storage devices due to their high theoretical energy density of $2600 \mathrm{Wh} \mathrm{kg}^{-1}$. ${ }^{[1]}$ However, their practical application is still hampered by three core hurdles. ${ }^{[2]}$ First, the insulating nature of orthorhombic sulfur with a very low conductivity of only $5 \times 10^{-28} \mathrm{~S} \mathrm{~m}^{-1}$ which impedes the sulfur utilization and decreases the rate capability of LSBs. Second, the notorious "shuttling of the LPSs" caused by dissolution and diffusion of intermediate polysulfides which reduces the discharge/charge capacity and causes the sluggish redox kinetics. Third, the unstable structure of the cathode due to massive volume change may disfigure the structure of cathodes and worsen the cycling performance of $\mathrm{LSBs}^{[3]}$ Fortunately, these key challenges can be minimized by rational

[a] Dr. R. Razaq, Prof. Z. Zhang

Institute of Catalysis for Energy and Environment, College of Chemistry and Chemical Engineering

Shenyang Normal University

Shenyang 110034, Liaoning, China

E-mail: chm_zhangzl@ujn.edu.cn

[b] Dr. R. Razaq, N. Zhang, Dr. Y. Xin, Dr. Q. Li, Dr. J. Wang, Prof. Z. Zhang School of Chemistry and Chemical Engineering, Shandong Provincial Key Laboratory of Fluorine Chemistry and Chemical Materials University of Jinan

Jinan, 250022, Shandong, China

[c] Dr. R. Razaq

University of Michigan-Shanghai Jiao Tong University Joint Institute Shanghai JiaoTong University

Supporting information for this article is available on the WWW under https://doi.org/10.1002/slct.202001729 weaved by biomass-derived CFs ensures the high electronic conductivity of the $\mathrm{MoS}_{2} / \mathrm{CFs}$ composite, sufficient electrode/ electrolyte interaction, fast electron and $\mathrm{Li}^{+}$transportation. Moreover, the CF network weaved from cost-effective tissue paper reduces the cost of LSBs. Thus, the $\mathrm{S}-\mathrm{MoS}_{2} / \mathrm{CFs}$ cathode exhibits a high rate capability (1149 and $608 \mathrm{~mA} \mathrm{~h} \mathrm{~g}^{-1}$ are obtained at $0.2 \mathrm{C}$ and $4 \mathrm{C}$, respectively), excellent cyclic performance with $\sim 75 \%$ capacity retention and $99 \%$ Coulombic efficiency at $2 \mathrm{C}$ after 500 cycles, corresponding to $\sim 0.05 \%$ capacity fading per cycle only, as well as structure integrity during the discharge/charge process.

design of multifunctional conductive macro-/nan o-/microstructured composite cathodes.

Till now, these composites fall into three categories. The first is conductive carbon, such as microporous carbon, ${ }^{[4]}$ mesoporous carbon, ${ }^{[5]}$ carbon fibers $(\mathrm{CFs}){ }^{[6]}$ carbon sphere, ${ }^{[7]}$ carbon nanotubes, ${ }^{[8,9]}$ and CF cloth. ${ }^{[10]}$ Owing to their electrically conductive pathways, these carbon materials serve as a physical barrier to confine the lithium polysulfides (LPSS). However, the physical confinement is not sufficient to trap LPSs. Over a long cycle life, sulfur species detached form nonpolar carbon are suspected to result in loss of active materials, increase of the charge transfer resistance, accumulation of insulating layers on the anode, and finally severe capacity fading.

Doped carbon with anchoring sites and effective electron pathway is designated as the second category. To provide anchoring sites for chemical adsorption of LPSs intermediates, the introduction of polar sites onto conductive carbon materials have been reported. For instance, graphene oxides, ${ }^{[1]}$ $\mathrm{B}$ and O-doped $\mathrm{CNT}^{[12]} \mathrm{N}$-doped graphene/CNT, ${ }^{[13]}$ B-doped graphene ${ }^{[14]} \mathrm{N}$-doped hollow carbon spheres, ${ }^{[15]} \mathrm{P}, \mathrm{N}$-codoped carbon nanospheres, ${ }^{[16]}$ and $\mathrm{N}$ or O-codoped carbon $^{[17]}$ have been widely explored for LSBs. The carbon materials contribute the conductive framework, while the doped sites on the conductive carbons enhance the chemical anchoring. However, the contents of doping atoms are not enough to control the flood of LPSs.

To further enhance the binding with LPSs, the third category, namely, polar and conductive transition metal compounds collaborated with carbon materials, such as transitional metal oxides, ${ }^{[18,19]}$ carbides, $^{[20]}$ nitrides, ${ }^{[21-23]}$ sulfides ${ }^{[24-27]}$ and porphyrin, ${ }^{[28]}$ have emerged to chemically adsorb LPSs. Generally, most of the previously reported transition metal 
composites are either micro-sized or bulk materials, restricting available anchoring sites towards LPSs. ${ }^{[29]}$ Recently, two dimensional (2D) layered transition metal dichalcogenides (TMDs) are attractive due to large exposed active surfaces for sulfur coverage and conversion. ${ }^{[30]} 2 \mathrm{D} \mathrm{MoS}_{2}$ is a typical member in the family of TMDs. ${ }^{[31]}$ Nevertheless, 2D MoS 2 nanosheets suffer from easy aggregation and limited conductivity. The former can be efficiently overcome by the hierarchical assembly of $2 \mathrm{D}$ nanosheets into 3 dimensional (3D) configurations ${ }^{[32]}$ and the latter is always solved by rationally coupling with carbon materials, for example, carbon nanotube and/or graphene. ${ }^{[33]}$

Herein, we designed and fabricated dense $\mathrm{MoS}_{2}$ microflowers assembled by cross-linked 2D MoS ${ }_{2}$ nanoflakes planting on biomass-derived $\mathrm{CF}$ network $\left(\mathrm{MoS}_{2} / \mathrm{CFs}\right)$ for multifunctional sulfur cathodes of LSBs. The 2D MoS 2 nanoflakes provide abundant anchoring sites for strong adsorption and redox conversion of LPSs, while the 3D flowerlike structure prevents lamellar aggregation of 2D MoS 2 nanoflakes. Importantly, the dense $\mathrm{MoS}_{2}$ micro-flowers planting on the network weaved by biomass-derived CFs ensures the high electronic conductivity of the $\mathrm{MoS}_{2} / \mathrm{CFs}$ composite, sufficient electrode/electrolyte interaction, fast electron and $\mathrm{Li}^{+}$transportation. Moreover, the large-scale production of biomass-derived conductive CFs from cost-effective tissue paper reduces the cost of LSBs. Thus, the $\mathrm{S}-\mathrm{MoS}_{2} / \mathrm{CFs}$ cathode achieves high sulfur retention and conversion as well as excellent electrochemical performance.

\section{Results and Discussion}

Scheme 1 depicts the synthesis procedure of the $\mathrm{MoS}_{2} / \mathrm{CFs}$. Commercial tissue paper interwoven by cellulose fibers is used as the growth substrate after purifying with $1 \mathrm{M} \mathrm{HCl}$. The purified tissue paper is immersed into a solution containing thiourea and ammonium molybdate tetrahydrate. Then, the slurry is hydrothermally treated at $180^{\circ} \mathrm{C}$ for $24 \mathrm{~h}$. After filtration and washing, the precipitate is calcined at $800^{\circ} \mathrm{C}$ in $\mathrm{Ar}$ in order to transform the tissue paper into CFs. The as-obtained $\mathrm{MoS}_{2} / \mathrm{CFs}$ was loaded with sulfur by vapor phase infusion method.

The carbonized tissue paper was first examined by Field emission scanning electron microscopy (FESEM) equipped with energy dispersive spectroscopy (EDS) and X-ray diffraction (XRD) (Figure S1), demonstrating the interwoven 3D network of $\mathrm{CFs}$. Then, the XRD pattern confirmed the presence of the $2 \mathrm{H}$ type $\mathrm{MoS}_{2}$ phase (JCPDS 37-1492) for $\mathrm{MoS}_{2} / \mathrm{CFs}$ (Figure 1a). Furthermore, the FESEM images of $\mathrm{MoS}_{2}$ /CFs show uniform and densely packed $\mathrm{MoS}_{2}$ flowers at a large scale on CFs (Figure 1b, c). Specifically, the low-magnification FESEM image shows that CFs retain the interwoven structure after supporting $\mathrm{MoS}_{2}$ flowers (Figure 1b). The interstitial area between CFs is useful for the penetration of electrolyte, thereby smoothing the redox conversion of LPSs. The high-magnification FESEM images of $\mathrm{MoS}_{2} / \mathrm{CFs}$ show that the $\mathrm{MoS}_{2}$ flowers consist of petals of thin 2D nanoflakes with a thickness of $\sim 10 \mathrm{~nm}$, which all radiate from the center and cross-link together (Figure 1c, d). The unique 3D structure of $\mathrm{MoS}_{2}$ flowers with numerous nanoflakes and nanovoids, not only hinders the $2 \mathrm{D}$ nanoflakes to entangle and restack but also brings efficient electron transfer due to linkage through CF networks. The Transmission electron microscopy (TEM) images of the $\mathrm{MoS}_{2}$ nanoflakes demonstrate an interlayer spacing of $0.62 \mathrm{~nm}$, corresponding to (002) plane of $\mathrm{MoS}_{2}$ (Figure. 1e, f), consistent with the XRD result. The content of $\mathrm{MoS}_{2}$ in the $\mathrm{MoS}_{2} / \mathrm{CFs}$ composite obtained by EDS is estimated to be $\sim 76 \mathrm{wt} \%$ (Figure S2).

The as-obtained $\mathrm{MoS}_{2} / \mathrm{CFs}$ composite are further evaluated by $\mathrm{N}_{2}$ adsorption/desorption isotherm measurement. The Brunauer-Emmett-Teller (BET) specifc surface area and pore volume are calculated to be $22.6 \mathrm{~m}^{2} / \mathrm{g}$ and $0.027 \mathrm{~cm}^{3} / \mathrm{g}$, respectively (Figure S3).

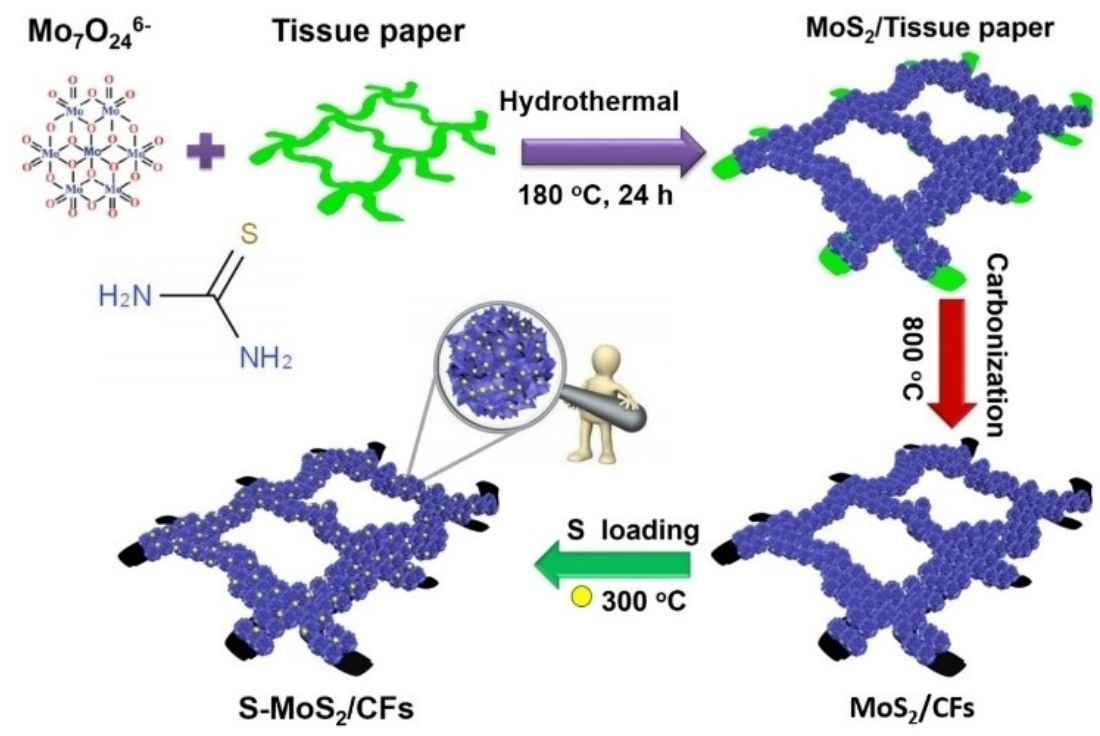

Scheme 1. Illustration for the preparation of $\mathrm{MoS}_{2} / \mathrm{CFs}$ and the sulfur loading using vapor phase infusion method. 

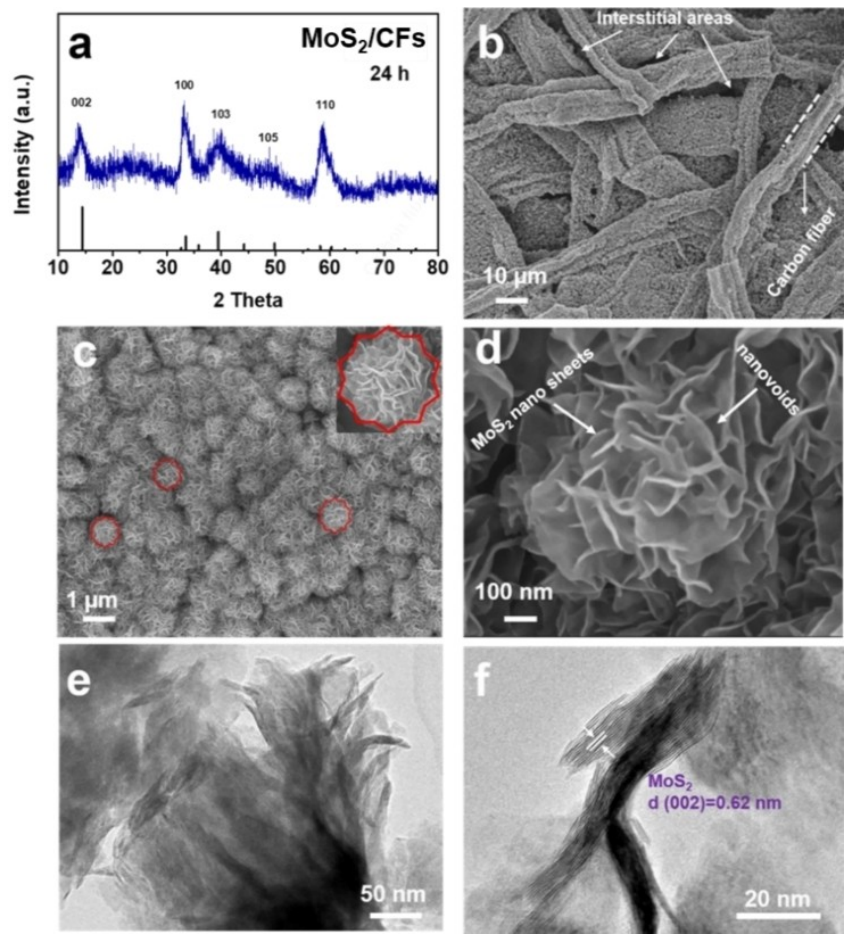

Figure 1. XRD pattern (a), FESEM images (b-d) and TEM images (e, $f$ ) of $M_{0} S_{2} /$ CFs.

X-ray photoelectron spectroscopy (XPS) survey shows the element composition of $\mathrm{C}, \mathrm{Mo}, \mathrm{S}$ and $\mathrm{O}$ in $\mathrm{MoS}_{2} / \mathrm{CFs}$ (Figure 2a). The high-resolution XPS spectra of $C, M o$ and $S$ were further recorded (Figure $2 b-d$ ). From $C$ 1s spectrum (Figure $2 b$ ), the $\mathrm{C}-\mathrm{C} / \mathrm{C}=\mathrm{C}, \mathrm{C}-\mathrm{O}$ and $\mathrm{C}=\mathrm{O}$ groups were observed at binding energies of $284.1,286.3$ and $288.6 \mathrm{eV}^{\left[{ }^{[3]}\right.}$ respectively. As expected, the Mo $3 \mathrm{~d}$ spectrum shows characteristic +4
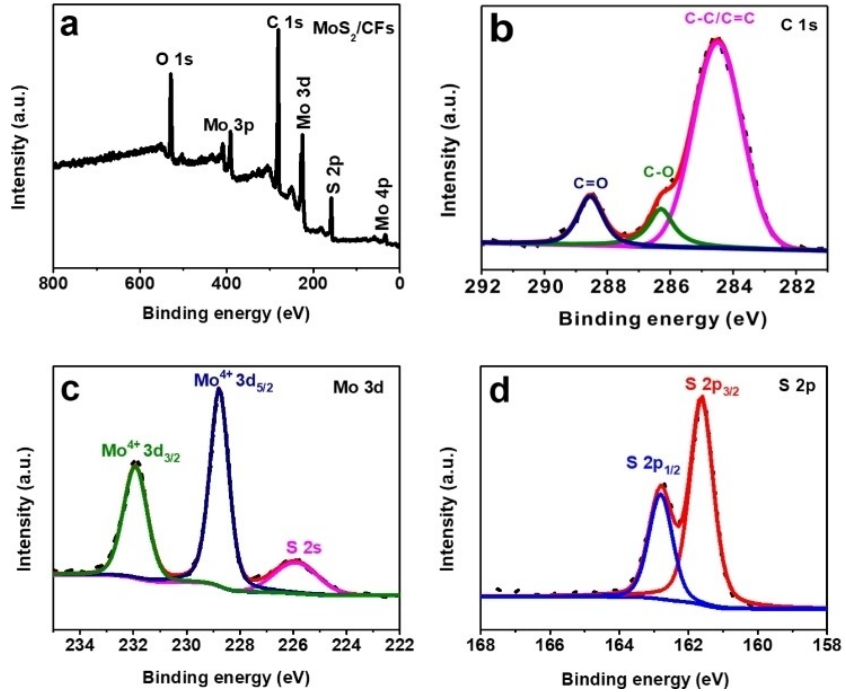

Figure 2. XPS spectra (a), high-resolution XPS spectra of $C$ 1s (b) Mo 3d (c), and $\mathrm{S} 2 \mathrm{p}(\mathrm{d})$ of $\mathrm{MoS}_{2} / \mathrm{CFs}$. oxidation state $^{[31]}$ (Figure 2c), corresponding to the assignment of the $S 2 p$ spectrum to sulfide ions $\left(S^{2-}\right)^{[31]}$ (Figure $2 d$ ), confirming the $\mathrm{MoS}_{2}$ surface.

The FESEM images show that the $\mathrm{S}-\mathrm{MoS}_{2} / \mathrm{CFs}$ composite well maintains the original morphology (Figure $3 a, b$ ), suggesting that no extra sulfur exists outside the $\mathrm{MoS}_{2} / \mathrm{CFs}$ structure. However, the composites after sulfur loading by both melt diffusion method ${ }^{[19]}$ (Figure S4a) and in situ oxidation method ${ }^{[26]}$ (Figure S4b) present sever aggregates of sulfur. EDX mappings of $\mathrm{S}-\mathrm{MoS}_{2} / \mathrm{CFs}$ show that sulfur is homogeneously distributed on the $\mathrm{MoS}_{2} / \mathrm{CFs}$ host (Figure 3c-f), indicating that sulfur has been successfully accommodated and immobilized on the surface and within the voids of $\mathrm{MoS}_{2} / \mathrm{CFs}$. XRD confirms the presence of sulfur ( $\mathrm{S}_{8}$, JCPDS 08-0247) (Figure 3g). The sulfur loading in $\mathrm{S}-\mathrm{MoS}_{2} / \mathrm{CFs}$ is determined by thermo-gravimetry analysis (TGA) to be $72 \mathrm{wt} . \%$ (Figure $3 \mathrm{~h}$ ). As a control sample, SCFs was also prepared by vapor phase infusion method (Figure S5), and TGA gives 66 wt.\% sulfur loading (Figure S6).

The electrochemical performances of the S-MoS $/ \mathrm{CFs}_{2}$ and SCFs cathodes were measured by fabricating 2025-type coin cells. Figure $4 a$ shows the cyclic performance of $\mathrm{S}-\mathrm{MoS}_{2} / \mathrm{CFs}$ and S-CFs at $0.5 \mathrm{C}$. The $\mathrm{S}-\mathrm{MoS}_{2} / \mathrm{CFs}$ electrode exhibits the discharge capacity of $1033.9 \mathrm{mAhg}^{-1}$ with $88 \%$ capacity retention after 100 cycles. Furthermore, the Coulombic efficiency is $\sim 100 \%$. By sharp contrast, S-CFs shows low discharge capacity with low capacity retention (78\%) after 100 cycles. Moreover, the discharge/charge plateau of S-MoS $/$ CFs shows a less hysteresis $(\triangle \mathrm{E}=0.18 \mathrm{~V})$ compared with that of $\mathrm{S}-\mathrm{C}(\triangle \mathrm{E}=$ $0.26 \mathrm{~V}$ ) (Figure $4 \mathrm{~b}$ ), suggesting the improved electrochemical kinetics of LPSs conversion on $\mathrm{MoS}_{2} /$ CFs. At a current density of
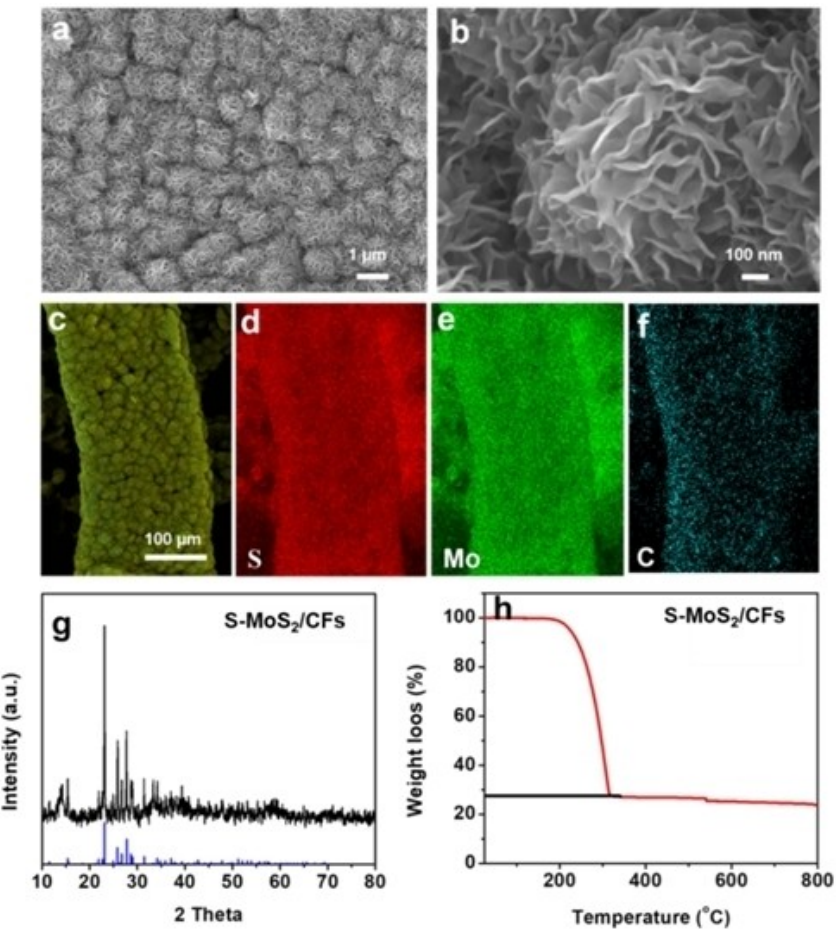

Figure 3. FESEM images and elemental mappings (a-f), XRD pattern (g) 
a

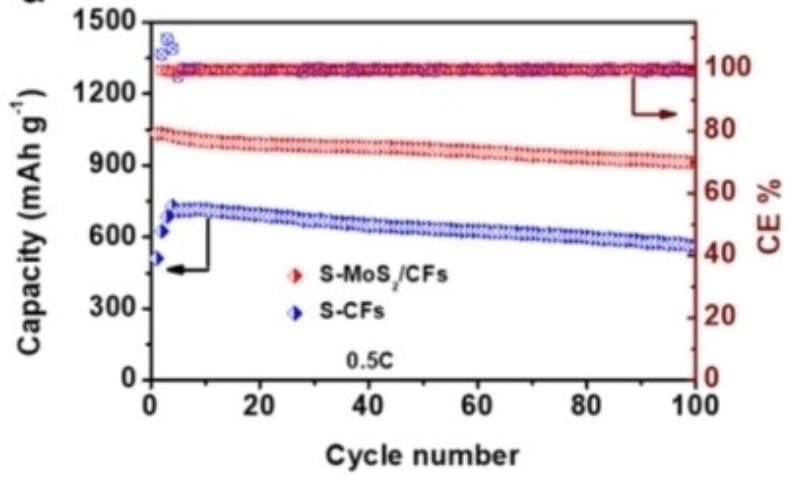

b

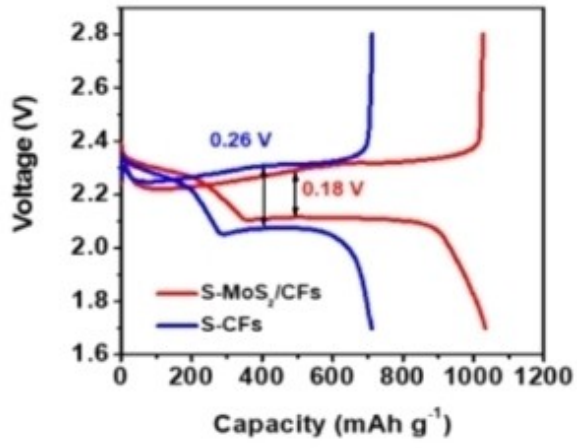

C

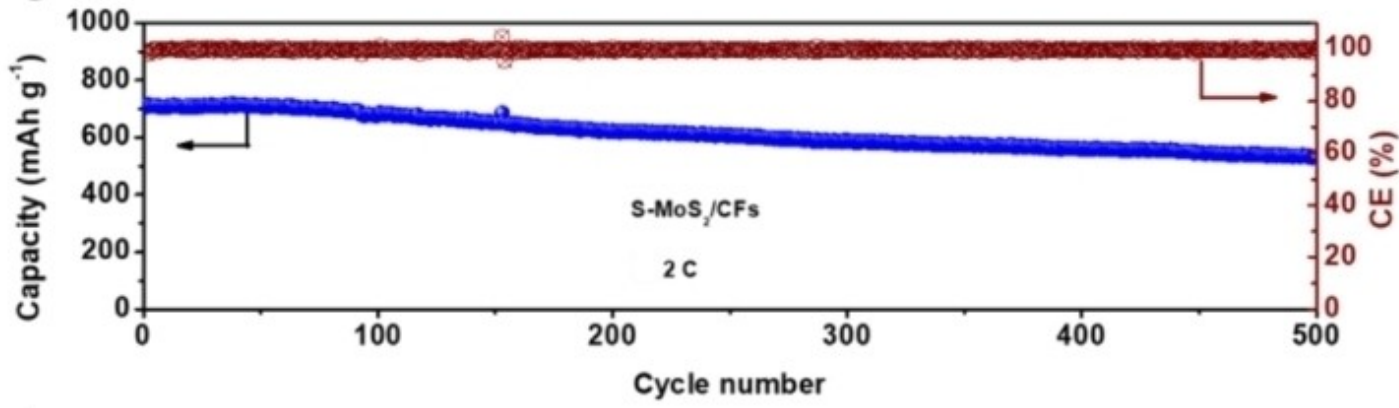

d

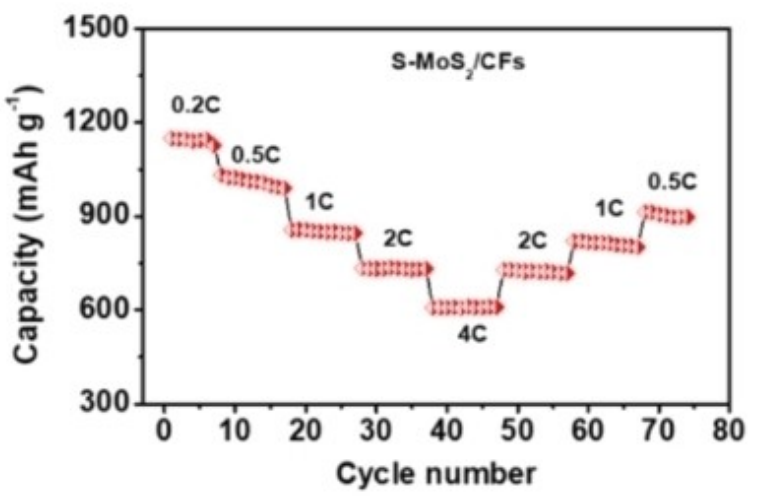

e

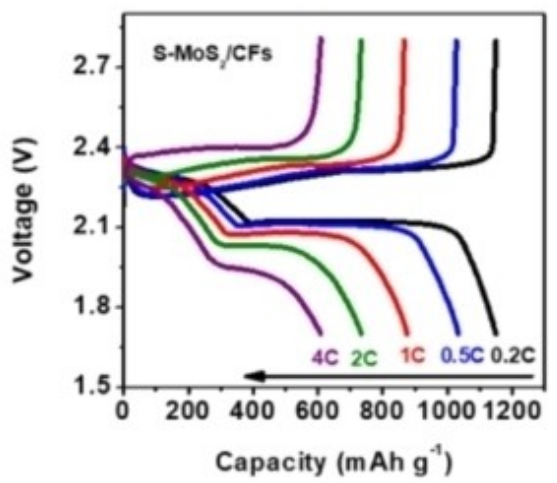

f

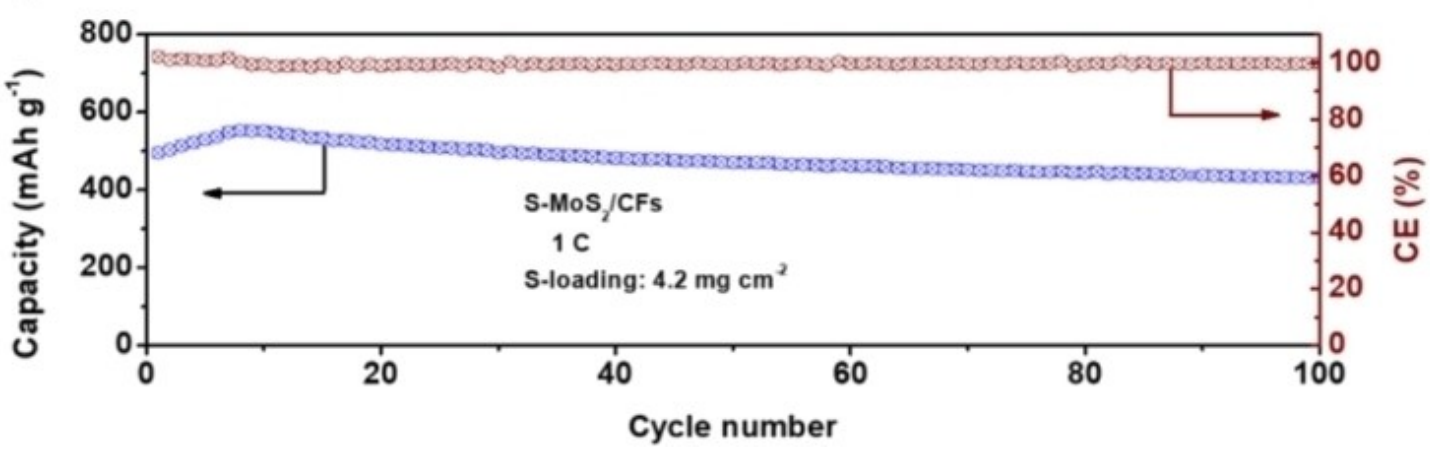

Figure 4. Cycling performance and Coulombic efficiency for the S-MoS $/$ /CFs and S-CFs cathodes at $0.5 \mathrm{C}$ over 100 cycles (a), galvanostatic discharge/charge curves for the S-MoS $/$ CFs and S-CFs cathodes at $0.5 \mathrm{C}$ (b), Long cyclic performance and Coulombic efficiency for S-MoS $2 / \mathrm{CFs}_{2}$ at $2 \mathrm{C}$ for 500 cycles (c), Rate performance (d), and Galvanostatic discharge/charge curves of the S-Mo $\mathrm{C}_{2} / \mathrm{HCFs}$ cathode at different current densities (e), Cycling performance and Coulombic efficiency of S-MoS $/$ CFs at $4.2 \mathrm{mg} \mathrm{cm}^{-2}$ areal sulfur loading and 100 cycles (f) 
$2 \mathrm{C}$, the specific capacity can reach up to 714 and retain $\sim 533 \mathrm{mAh}^{-1}$ (with $\sim 75 \%$ retention) after 500 cycles with $99 \%$ Coulombic efficiency, corresponding to $\sim 0.05 \%$ capacity fading per cycle only (Figure 4c).

Figure $4 \mathrm{~d}$ shows the rate performance of $\mathrm{S}-\mathrm{MoS}_{2} / \mathrm{CFs}$. The specific capacities at the current densities of $0.2 \mathrm{C}, 0.5 \mathrm{C}, 1 \mathrm{C}$, $2 \mathrm{C}$, and $4 \mathrm{C}$ are 1149, 1027, 856, 723, and $608 \mathrm{~mA} \mathrm{~h} \mathrm{~g}^{-1}$, respectively. Evidently, good capacity reversibility $(913 \mathrm{~mA} \mathrm{~h}$ $\mathrm{g}^{-1}$ ) is achieved at $0.5 \mathrm{C}$. Figure $4 \mathrm{e}$ shows the galvanostatic discharge/charge profiles of $\mathrm{S}-\mathrm{MoS}_{2} / \mathrm{CFs}$ at C-rates of $0.2 \mathrm{C}$ to $4 \mathrm{C}$. The typical multi-step reduction reactions with two reaction plateaus can be observed in the discharge process. The upper reduction plateau comprises of reduction of sulfur into long-chain LPSs, and the lower plateau is assigned to the subsequent formation of short-chain LPSs to $\mathrm{Li}_{2} \mathrm{~S}$, whereas the charge plateau corresponds to the transformation of $\mathrm{Li}_{2} \mathrm{~S}_{2} / \mathrm{Li}_{2} \mathrm{~S}$ to $\mathrm{Li}_{2} \mathrm{~S}_{8} / \mathrm{S}_{8}$. Importantly, the galvanostatic discharge/charge voltage profile of S-MoS $/$ CFs at $4 \mathrm{C}$ is still obvious.

The thick electrode with high areal sulfur loading is crucially important for practical LSBs. ${ }^{[35]}$ The cyclic performance of S$\mathrm{MoS}_{2} / \mathrm{CFs}$ with a high sulfur loading of $4.2 \mathrm{mg} \mathrm{cm}^{-2}$ was further investigated at $1 \mathrm{C}$ (Figure $4 \mathrm{f}$ ). The $\mathrm{S}-\mathrm{MoS}_{2} / \mathrm{CFs}$ cathode shows high discharge capacity of $553 \mathrm{mAhg}^{-1}$ at $1 \mathrm{C}$ corresponds to $85 \%$ capacity retention over 100 cycles. Furthermore, the corresponding Coulombic efficiency is stabilized around $99 \%$ after 100 cycles.

The excellent electrochemical performance is supposed from the multifunctional effects of $\mathrm{MoS}_{2} / \mathrm{CFs}$. First, the LPSs adsorption experiments were performed. $\mathrm{MoS}_{2} / \mathrm{CFs}$ and CFs are dispersed separately into the pristine $\mathrm{Li}_{2} \mathrm{~S}_{4}$ solution with stirring for $30 \mathrm{~min}$ and left undisturbed for $12 \mathrm{~h}$. As observed in Figure 5a, a distinctive change in color was observed for $\mathrm{MoS}_{2} /$ $\mathrm{CFs}$, indicating the stronger trapping ability of $\mathrm{MoS}_{2} / \mathrm{CFs}$ for LPSs in comparison with CFs.

Secondly, cyclic voltammetry (CV) tests were performed for symmetric cells within a voltage range of -0.7 to $+0.7 \mathrm{~V}^{[25]}$ (Figure 5b). The increased current density of $\mathrm{MoS}_{2} / \mathrm{CFs}$ over CFs demonstrates the enhanced kinetics of the redox reactions and the reduced overpotential for LPSs conversion, which is direct evidence of polysulfide electrocatalysis on $\mathrm{MoS}_{2} / \mathrm{CFs} .^{[23,36]}$ Furthermore, electrochemical impedance spectroscopy (EIS) measured on symmetric cells reveals a low charge transfer resistance $\left(R_{\mathrm{ct}}\right)$ for $\mathrm{MoS}_{2} / \mathrm{CFs}$ (Figure $5 \mathrm{c}$ ), which is another evidence of the electrocatalytic effects derived from the unique 3D architecture of uniformly dispersed $\mathrm{MoS}_{2}$ flowers interconnected with CF

Thirdly, $\mathrm{Li}^{+}$ion diffusion is often a bottleneck during the electrochemical reaction process in LSBs. CV curves for S-MoS $/$ CFs (Figure S7) and S-CFs (Figure S8) were performed at different scan rates, which exhibit two cathodic peaks (I and II) and one anodic peak (III). Note that the cathodic peak I at low scan rates $\left(0.1\right.$ and $\left.0.2 \mathrm{mV} \mathrm{s}^{-1}\right)$ for S-CFs is discerned two peaks, maybe due to two types of anchoring sites based on XPS, such as $\mathrm{C}-\mathrm{C} / \mathrm{C}=\mathrm{C}$ and $\mathrm{C}=\mathrm{O} / \mathrm{C}-\mathrm{O}$ species (Figure $2 \mathrm{~b}$ ). However, no split was observed for $\mathrm{S}-\mathrm{MoS}_{2} / \mathrm{CFs}$, because the dense coverage of CFs by 3D MoS ${ }_{2}$ flowers minimized the contact between CFs and electrolyte, which depressed the absorption and conversion of LPSs on CFs. ${ }^{[37]}$ Furthermore, the high current density
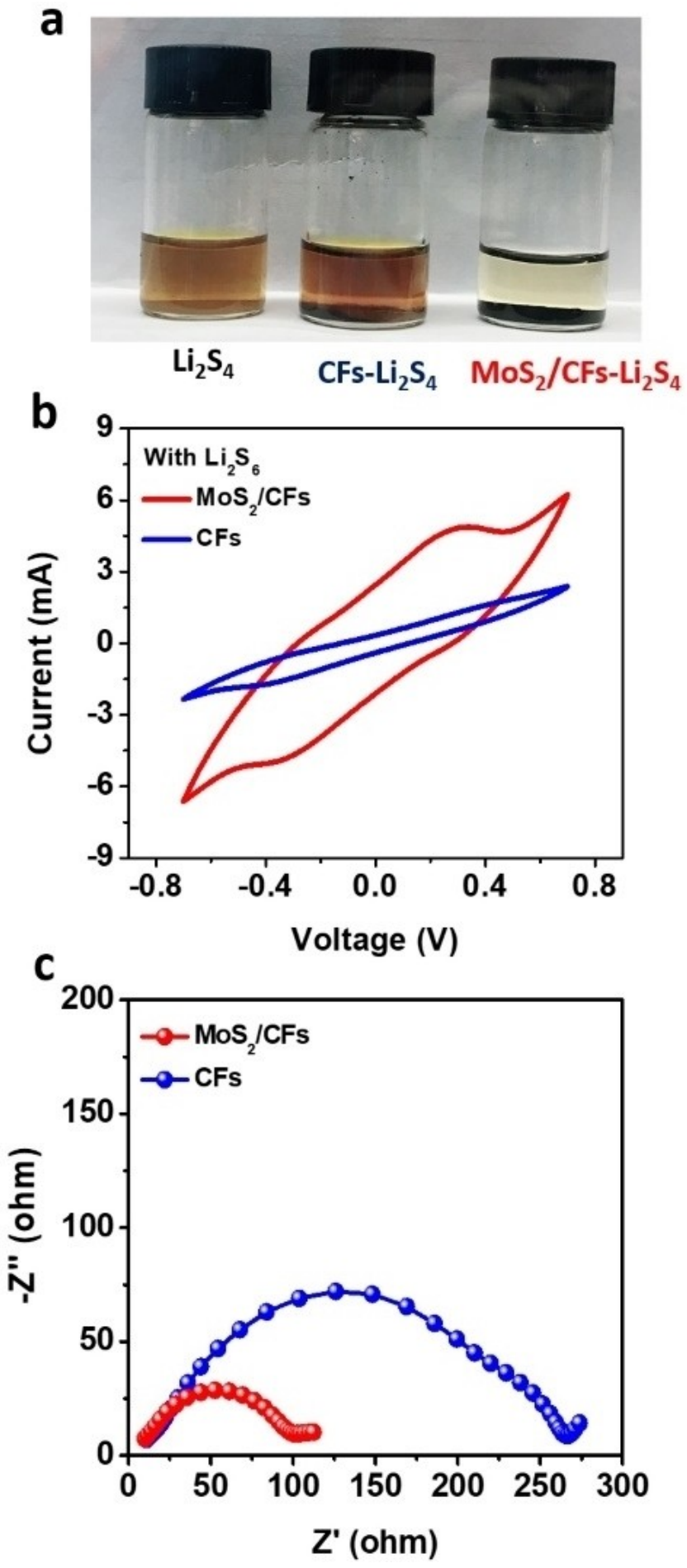

Figure 5. Visualized adsorption of $\mathrm{Li}_{2} \mathrm{~S}_{4}$ on $\mathrm{MoS}_{2} / \mathrm{CFs}$ and CFs (a), Polarization curves (b) and EIS spectra (c) of symmetrical cells for $\mathrm{MoS}_{2} / \mathrm{CFs}$ and CFs.

for $\mathrm{S}-\mathrm{MoS}_{2} / \mathrm{CFs}$ suggests that the cell polarization decreases and the participation of active materials on redox reactions increases, consistent with discharge/charge profiles. In addition, as the scan rates increase, the S-MoS$/$ CFs electrode displays a less decrease in onset potentials for peaks I, II, and III (Figure. $6 a$, b) than S-CFs (Figure 6c, d), demonstrating the accelerated 
a

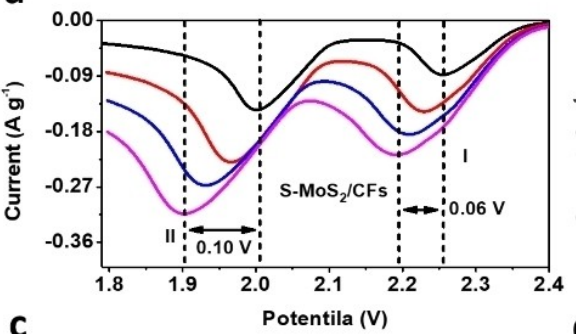

C

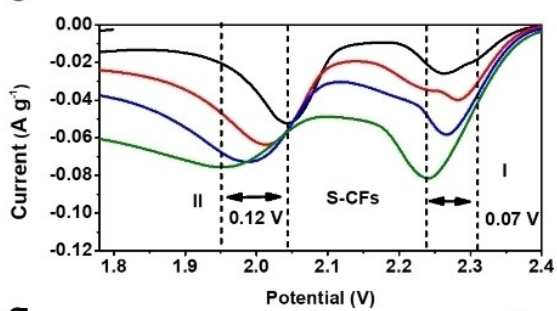

g
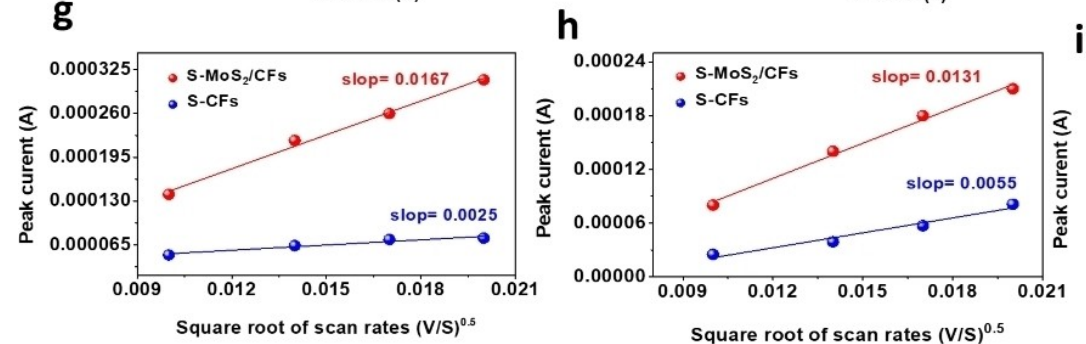

Square root of scan rates $(\mathrm{V} / \mathrm{S})^{0.5}$

e

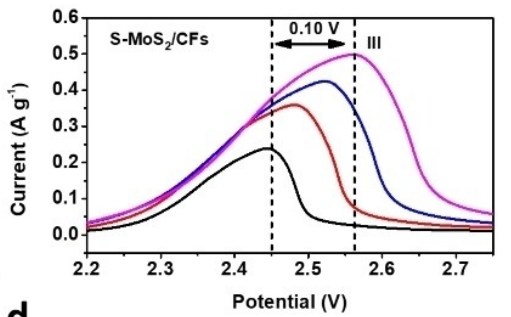

d
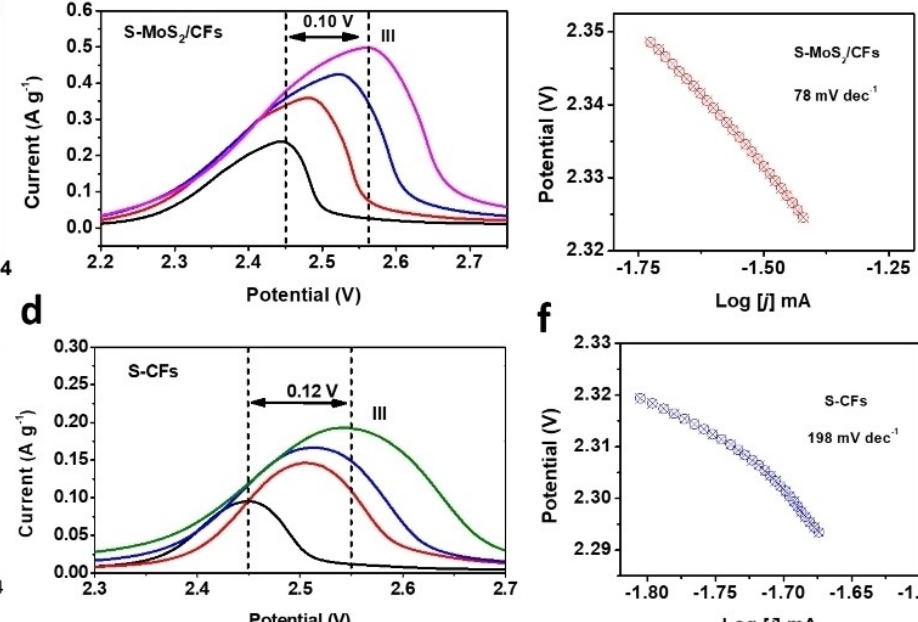

f

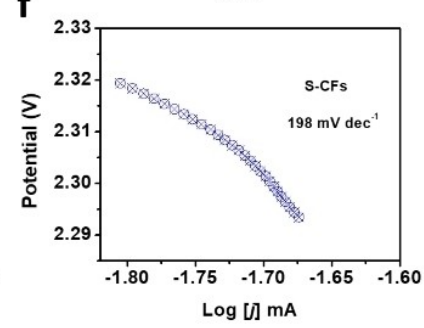

i

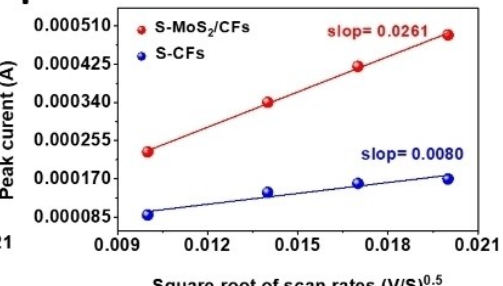

Figure 6. The CV data of $\mathrm{MoS}_{2} / \mathrm{CFs}(\mathrm{a}, \mathrm{b})$ and S-CFs (c, d) at different scan rates. Tafel plots of $\mathrm{MoS}_{2} / \mathrm{CFs}(\mathrm{e})$ and S-CFs (f). Plots of peak currents versus the square root of scan rates for $\mathrm{MoS}_{2} / \mathrm{CFs}$ and S-CFs: the cathodic reaction I $\left(\mathrm{S}_{8}-\mathrm{Li}_{2} \mathrm{~S}_{4}\right)(\mathrm{g})$, the cathodic reaction II $\left(\mathrm{Li}_{2} \mathrm{~S}_{4}-\mathrm{Li}_{2} \mathrm{~S}\right)(\mathrm{h})$, and the anodic reaction III $\left(\mathrm{Li}_{2} \mathrm{~S}-\mathrm{S}_{8}\right)(\mathrm{i})$

redox conversion of LPSs on $\mathrm{MoS}_{2} / \mathrm{CFs}^{[22,38]}$ The electrocatalytic effect was also analyzed by Tafel slope using the CV curve at $0.1 \mathrm{mV} \mathrm{s}^{-1}$. S-MoS $/$ CFs displays Tafel slope of $78 \mathrm{mV} \mathrm{dec}^{-1}$ (Figure 6e), much smaller than that of S-CFs $\left(198 \mathrm{mV} \mathrm{dec}^{-1}\right)$ (Figure $6 \mathrm{f}$ ), suggesting the enhanced redox kinetics of LPSs over S-MoS $2 / \mathrm{CFs}^{[39,40]}$

The $\mathrm{Li}^{+}$diffusion was explored under different scanning rates ranging from 0.1 to $0.4 \mathrm{mV} \mathrm{s}^{-1}$. As shown in Figure $6 \mathrm{~g}$-i, all cathodic and anodic peak currents are linear with the square root of scan rates, from which the $\mathrm{Li}^{+}$diffusion rate can be estimated using the classical Randles Sevcik equation: ${ }^{[41]}$

$I_{\mathrm{p}}=\left(2.69 \times 10^{5}\right) n^{1.5} S D_{\mathrm{Li}}^{0.5} C_{\mathrm{Li}} v^{0.5}$

Where $I_{p}$ is the peak current, $n$ is the charge transfer number, $S$ is the surface area of the electrode, $D_{\mathrm{Li}}$ is the $\mathrm{Li}^{+}$ diffusion coefficient, $C_{\mathrm{Li}}$ is $\mathrm{Li}^{+}$concentration, and $v$ is the scan rate. Because $n, S$, and $C_{\mathrm{Li}}$ are unchanged, the slope of the line $\left(I_{\mathrm{p}} / v^{0.5}\right)$ represents the $\mathrm{Li}^{+}$diffusion rate. As observed in Fig. $6 \mathrm{~g}$ $\mathrm{i}$, the $\mathrm{Li}^{+}$diffusion rate is higher for $\mathrm{S}-\mathrm{MoS}_{2} / \mathrm{CFs}$ compared with $\mathrm{S}-\mathrm{CF}$. The enhanced $\mathrm{Li}^{+}$diffusion further promotes the catalytic effect of $\mathrm{MoS}_{2} / \mathrm{CFs}$, which is a critical factor determining the battery performance.

Figure 7a schematically illustrates the LPSs adsorption, electrocatalytic electron and $\mathrm{Li}^{+}$transfer effects. The unique 3D $\mathrm{MoS}_{2}$ flowers provide numerous nanoflakes and nanovoids for polysulfides retention and electrocatalytic conversion as well as
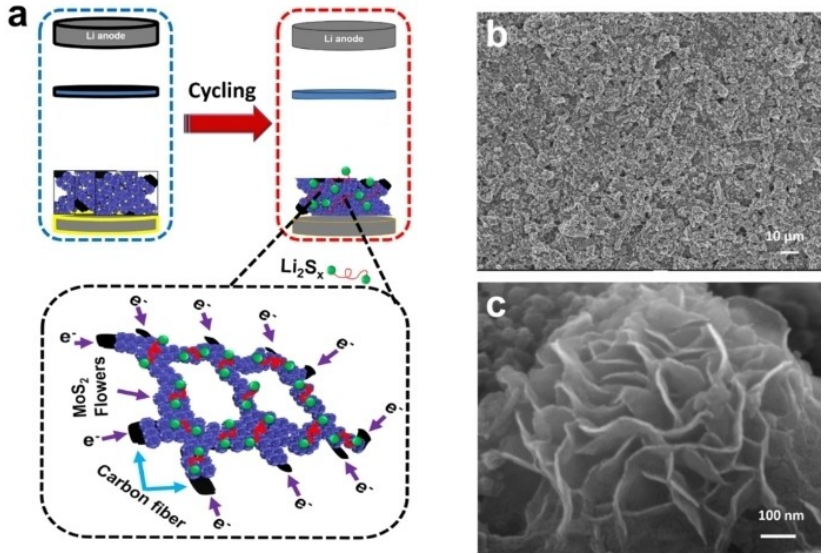

Figure 7. Schematic illustration of the mechanisms during redox reactions (a), FESEM images of $\mathrm{MoS}_{2} /$ CFs after cycling (b, c).

$\mathrm{Li}^{+}$diffusion. Simultaneously, electrons can be effectively collected and transferred to CFs. To further validate the superiority of $\mathrm{S}-\mathrm{MoS}_{2} / \mathrm{CFs}$ after long cycling, the cells are disassembled at fully charging state. FESEM shows that the morphology of the S-MoS 2 /CFs cathode is well maintained after cycling (Figure $7 \mathrm{~b}, \mathrm{c}$ ), confirming mechanical robustness of $\mathrm{MoS}_{2} / \mathrm{CFs}$. Just recently, Qiao and co-authors proposed that the practical route for $\mathrm{Li}-\mathrm{S}$ battery commercialization is fabrication of 3D electrodes from 2D sulfides to take full advantage of their 
multiple functions. ${ }^{[42]}$ Here, the developed $\mathrm{MoS}_{2} / \mathrm{CF}$ s is the right choice to meet this requirement. Compared with similar systems published in top journals (Table S1), S-MoS 2 /CFs outperforms in terms of initial capacity, capacity retention and Coulombic efficiency in the state of the art LSBs batteries.

\section{Conclusion}

In summary, the dense MoS2 micro-flowers assembled by cross-linked 2D MoS2 nanoflakes planting on biomass-derived CF network (MoS2/CFs) are fabricated as sulfur cathodes of LSBs. The specific architecture possesses multiple functions: (i) prevents lamellar aggregation of 2D nanoflakes; (ii) minimizes the interface between CFs and the electrolyte; (iii) supplies abundant anchoring sites for adsorption and catalytic conversion of LPSs; (iv) enables sufficient electrode/electrolyte interaction and fast electron transfer; ( $v$ ) promotes the $\mathrm{Li}+$ ion transportation. Furthermore, the CF network derived from tissue paper is cost-effective. Thus, the S-MoS2/CFs cathode exhibits a high rate capability (1149 and $608 \mathrm{~mA} \mathrm{~h} \mathrm{g-1}$ are obtained at $0.2 \mathrm{C}$ and $4 \mathrm{C}$, respectively) and excellent cyclic performance with $\sim 75 \%$ capacity retention and $99 \%$ Coulombic efficiency at $2 \mathrm{C}$ after 500 cycles, corresponding to $\sim 0.05 \%$ capacity fading per cycle only. Remarkably, the structural integrity of the $\mathrm{MoS}_{2}$ flowers is still preserved even after long cycling.

\section{Supporting Information Summary}

Sample synthesis, sample characterization and electrochemical measurements are given in detail in supporting information.

\section{Acknowledgements}

This work was supported by LiaoNing Revitalization Talents Program (No. XLYC1802076) and National Natural Science Foundation of China (No. 21876061, 21906063 and 21805112).

\section{Conflict of Interest}

The authors declare no conflict of interest.

Keywords: Biomass-derived carbon fiber network - Dense $\mathrm{MoS}_{2}$ micro-flower • Lithium • Polysulfide adsorption • Redox chemistry

[1] Q. Pang, X. Liang, C. Y. Kwok, L. F. Nazar, Nat. Energy 2016, 1,16132.

[2] J. He, A. Manthiram, Energy Storage Mater. 2019, 20, 55-70.

[3] a) A. Manthiram, Y. Fu, S. H. Chung, C. Zu, Y. S. Su, Chem. Rev. 2014, 114, 11751-11787; b) X. Liu, J. Q. Huang, Q. Zhang, L. Mai, Adv. Mater. 2017, 29, 1601795.

[4] Z. Li, L. Yuan, Z. Yi, Y. Sun, Y. Liu, Y. Jiang, Y. Shen, Y. Xin, Z. Zhang, Y. Huang, Adv. Energy Mater. 2014, 4, 1301473.

[5] D. Li, F. Han, S. Wang, F. Cheng, Q. Sun, W. C. Li, ACS Appl. Mater. Interfaces 2013, 5, 2208-2213.

[6] G. Zheng, Q. Zhang, J. J. Cha, Y. Yang, W. Li, Z. W. Seh, Y. Cui, Nano Lett. 2013, 13, 1265-1270.

[7] N. Jayaprakash, J. Shen, S. S. Moganty, A. Corona, L. A. Archer, Angew. Chem. Int. Ed. 2011, 50, 5904-5908; Angew. Chem. 2011, 123, 6026-6030.
[8] X.-B. Cheng, J.-Q. Huang, Q. Zhang, H.-J. Peng, M.-Q. Zhao, F. Wei, Nano Energy 2014, 4, 65-72.

[9] L. Wang, Z. Yang, H. Nie, C. Gu, W. Hua, X. Xu, X. a Chen, Y. Chen, S. Huang, J. Mater. Chem. A 2016, 4, 15343-15352.

[10] R. Elazari, G. Salitra, A. Garsuch, A. Panchenko, D. Aurbach, Adv. Mater. 2011, 23, 5641-5644.

[11] L. Ji, M. Rao, H. Zheng, L. Zhang, Y. Li, W. Duan, J. Guo, E. J. Cairns, Y. Zhang, J. Am. Chem. Soc. 2011, 133, 18522-18525.

[12] C. Jin, W. Zhang, Z. Zhuang, J. Wang, H. Huang, Y. Gan, Y. Xia, C. Liang, J. Zhang, X. Tao, J. Mater. Chem. A 2017, 5, 632-640.

[13] D. Su, M. Cortie, G. Wang, Adv. Energy Mater. 2017, 7, 1602014.

[14] P. Shi, Y. Wang, X. Liang, Y. Sun, S. Cheng, C. Chen, H. Xiang, ACS Sustainable Chem. Eng. 2018, 6, 9661-9670.

[15] W. Zhou, X. Xiao, M. Cai, L. Yang, Nano Lett. 2014, 14, 5250-5256.

[16] J. Wang, H. Yang, Z. Chen, L. Zhang, J. Liu, P. Liang, H. Yang, X. Shen, Z. X. Shen, Adv. Sci. 2018, 5, 1800621.

[17] M. Chen, S. Jiang, S. Cai, X. Wang, K. Xiang, Z. Ma, P. Song, A. C. Fisher, Chem. Engineering J. 2017, 313, 404.

[18] a) H. Wang, T. Zhou, D. Li, H. Gao, G. Gao, A. Du, H. Liu, Z. Guo, ACS Appl. Mater. Interfaces 2017, 9, 4320-4325; b) Z. Li, J. Zhang, B. Guan, D. Wang, L.-M. Liu, X. W. Lou, Nat. Commun. 2016, 7, 13065; c) S. Imtiaz, Z. A. Zafar, R. Razaq, D. Sun, Y. Xin, Q. Li, Z. Zhang, L. Zheng, Y. Huang, J. A. Anderson, Adv. Mater. Interfaces 2018, 5, 1800243.

[19] R. Razaq, D. Sun, Y. Xin, Q. Li, T. Huang, Z. Zhang, Y. Huang, Adv. Mater. Interfaces 2019, 6, 1801636.

[20] a) B. Cao, Y. Chen, D. Li, L. Yin, Y. Mo, ChemSusChem 2016, 9, 3338-3344; b) W. Bao, D. Su, W. Zhang, X. Guo, G. Wang, Adv. Funct. Mater. 2016, 20, 8746-4756; c) R. Razaq, D. Sun, Y. Xin, Q. Li, T. Huang, L. Zheng, Z. Zhang, Y. Huang, Nanotechnology 2018, 29, 295401; d) Y. Wu, X. Zhu, P. Li, T. Zhang, M. Li, J. Deng, Y. Huang, P. Ding, S. Wang, R. Zhang, J. Lu, G. Lu, Y. Li, Y. Li, Nano Energy 2019, 59, 636-643; e) R. Razaq, N. Zhang, Y. Xin, Q. Li, J. Wang, Z. Zhang, EcoMat DOI 10.1002/eom2.12020.

[21] a) Z. Cui, C. Zu, W. Zhou, A. Manthiram, J. B. Goodenough, Adv. Mater. 2016, 28, 6926; b) Z. Sun, J. Zhang, L. Yin, G. Hu, R. Fang, H. M. Cheng, F. Li, Nat. Commun. 2017, 8, 14627 .

[22] W. G. Lim, C. Jo, A. Cho, J. Hwang, S. Kim, J. W. Han, J. Lee, Adv. Mater. 2019, 31, 1806547.

[23] M. Zhao, H. J. Peng, B. Q. Li, X. Chen, J. Xie, X. Liu, Q. Zhang, J. Q. Huang, Angew. Chem. Int. Ed. 2020, 59, 9011.

[24] a) T. Chen, Z. Zhang, B. Cheng, R. Chen, Y. Hu, L. Ma, G. Zhu, J. Liu, Z. Jin, J. Am. Chem. Soc. 2017, 139, 12710-12715; b) H. Zhang, M. Zou, W. Zhao, Y. Wang, Y. Chen, Y. Wu, L. Dai, A. Cao, ACS Nano 2019, 13, 39823991; c) X. Yang, X. Gao, Q. Sun, S. P. Jand, Y. Yu, Y. Zhao, X. Li, K. Adair, L. Y. Kuo, J. Rohrer, J. Liang, X. Lin, M. N. Banis, Y. Hu, H. Zhang, X. Li, R. Li, H. Zhang, P. Kaghazchi, T. K. Sham, X. Sun, Adv. Mater. 2019, 31, 1901220.

[25] Z. Yuan, H. J. Peng, T. Z. Hou, J. Q. Huang, C. M. Chen, D. W. Wang, X. B. Cheng, F. Wei, Q. Zhang, Nano Lett. 2016, 16, 519-527.

[26] R. Razaq, D. Sun, J. Wang, Y. Xin, G. Abbas, J. Zhang, Q. Li, T. Huang, Z. Zhang, Y. Huang, J. Power Sources 2019, 414, 453-459.

[27] M. Chen, W. Xu, S. Jamil, S. Jiang, C. Huang, X. Wang, Y. Wang, H. Shu, K Xiang, P. Zeng, Small 2018, 14, 1803134.

[28] B.-Q. Li, H.-J. Peng, X. Chen, S.-Y. Zhang, J. Xie, C.-X. Zhao, Q. Zhang, CCS Chem. 2019, 1, 128-137.

[29] P. T. Dirlam, J. Park, A. G. Simmonds, K. Domanik, C. B. Arrington, J. L. Schaefer, V. P. Oleshko, T. S. Kleine, K. Char, R. S. Glass, C. L. Soles, C. Kim, N. Pinna, Y. E. Sung, J. Pyun, ACS Appl. Mater. Interfaces 2016, 8, 1343713848.

[30] H. Lin, L. Yang, X. Jiang, G. Li, T. Zhang, Q. Yao, G. W. Zheng, J. Y. Lee, Energy Environ. Sci. 2017, 10, 1476-1486.

[31] G. Liu, A. W. Robertson, M. M.-J. Li, W. C. H. Kuo, M. T. Darby, M. H. Muhieddine, Y.-C. Lin, K. Suenaga, M. Stamatakis, J. H. Warner, S. C. E. Tsang, Nat. Chem. 2017,9, 810-816.

[32] X. Yang, Q. Li, E. Lu, Z. Wang, X. Gong, Z. Yu, Y. Guo, L. Wang, Y. Guo, W. Zhan, J. Zhang, S. Dai, Nat. Commun. 2019, 10, 1611.

[33] W. Xue, Z. Shi, L. Suo, C. Wang, Z. Wang, H. Wang, K. P. So, A. Maurano, D. Yu, Y. Chen, L. Qie, Z. Zhu, G. Xu, J. Kong, J. Li, Nat. Energy 2019, 4, 374-382.

[34] I. S. Amiinu, Z. Pu, X. Liu, K. A. Owusu, H. G. R. Monestel, F. O. Boakye, H. Zhang, S. Mu, Adv. Funct. Mater. 2017, 27, 1702300. 
[35] X. Tang, Z. Sun, H. Yang, H. Fang, F. Wei, H.-M. Cheng, S. Zhuo, F. Li, J. Energy Chem. 2019, 31, 119.

[36] X. Huang, J. Tang, B. Luo, R. Knibbe, T. Lin, H. Hu, M. Rana, Y. Hu, X. Zhu, Q. Gu, D. Wang, L. Wang, Adv. Energy Mater. 2019, 9, 1901872.

[37] X. Xie, T. Makaryan, M. Zhao, K. L. Van Aken, Y. Gogotsi, G. Wang, Adv. Energy Mater. 2016, 6, 1502161.

[38] Y. Li, P. Xu, G. Chen, J. Mou, S. Xue, K. Li, F. Zheng, Q. Dong, J. Hu, C. Yang, M. Liu, Chem. Eng. J. 2020, 380, 122595.

[39] Z. Zeng, W. Li, Q. Wang, X. Liu, Adv. Sci. 2019, 6, 1900711.
[40] M. Zhao, H. J. Peng, Z. W. Zhang, B. Q. Li, X. Chen, J. Xie, X. Chen, J. Y. Wei, Q. Zhang, J. Q. Huang, Angew. Chem. Int. Ed. 2019, 58, 3779.

[41] Y. Song, W. Zhao, X. Zhu, L. Zhang, Q. Li, F. Ding, Z. Liu, J. Sun, ACS Appl. Mater. Interfaces 2018, 10, 15733-15741.

[42] C. Ye, D. Chao, J. Shan, H. Li, K. Davey, S.-Z. Qiao, Matter 2020, 2, 323344.

Submitted: April 27, 2020

Accepted: June 22, 2020 